\title{
Methotrexate use, not interleukin 33, is associated with lower carotid intima-media thickness in patients with rheumatoid arthritis
}

\author{
Maria Raquel Costa Pinto ${ }^{7^{*}}$ D, Adriana Maria Kakehasi ${ }^{1}$, Adriano José Souza ${ }^{2}$, Wilson Campos Tavares Jr ${ }^{3}$, \\ Monaliza Angela Rocha', Cyntia Gabriele Michel Cardoso Trant ${ }^{1}$ and Marcus Vinicius Andrade ${ }^{1}$
}

\begin{abstract}
Background: Rheumatoid arthritis is a risk factor for early mortality due to cardiovascular disease. Interleukin-33 appears to protect against the development of atherosclerosis. The purpose of this study was to investigate the relationship between serum levels of interleukin-33 and its soluble receptor with the presence of subclinical carotid atherosclerosis in rheumatoid arthritis patients.

Methods: Rheumatoid arthritis patients without atherosclerotic disease were subjected to clinical and laboratory assessments, including carotid ultrasound. Interleukin-33 and its soluble receptor serum levels were measured by ELISA.

Results: 102 patients were included. The prevalence of carotid plaques was $23.5 \%$ and the median intima-media thickness was $0.7 \mathrm{~mm}$. The median interleukin-33 and its soluble receptor concentration was 69.1 and $469.8 \mathrm{pg} / \mathrm{ml}$. No association was found between serum interleukin-33 or its soluble receptor and intima-media thickness or plaque occurrence. Each $0.1 \mathrm{~mm}$ increase of intima-media thickness raised the odds of plaque occurrence by 5.3-fold, and each additional year of rheumatoid arthritis duration increased the odds of plaque occurrence by $6 \%$. Each additional year in patients age and each one-point increase in the Framingham Risk Score were associated with a $0.004 \mathrm{~mm}$ and $0.012 \mathrm{~mm}$ increase in intima-media thickness. Methotrexate use was associated with a $0.07 \mathrm{~mm}$ reduction in intima-media thickness.

Conclusions: Interleukin-33 and its soluble receptor were not associated with subclinical atherosclerosis. Traditional risk factors for atherosclerosis and rheumatoid arthritis duration were associated with intima-media thickness and plaque occurrence; methotrexate use was associated with a lower intima-media thickness.
\end{abstract}

Keywords: Rheumatoid arthritis, Cardiovascular diseases, Interleukins, Methotrexate

\section{Background}

Rheumatoid arthritis (RA) is an autoimmune inflammatory disease that can lead to articular destruction. Fibroblast-like synoviocytes are local producers of inflammatory interleukins, including interleukin 33 (IL-33). IL-33 is a member of the IL-1 family that modulates the immune response by inducing cytokine production by type $2 \mathrm{~T}$ helper lymphocytes (Th2). IL-33 is a ligand for receptor ST2, a member of the

\footnotetext{
* Correspondence: dramariaraquel@gmail.com

${ }^{1}$ School of Medicine, Federal University of Minas Gerais (Universidade Federal de Minas Gerais - UFMG), Avenida Alfredo Balena, 190, Bairro Santa Efigênia, Belo Horizonte, Minas Gerais CEP 30130-100, Brazil

Full list of author information is available at the end of the article
}

IL1R/TLR superfamily. Increased levels of soluble ST2 (sST2) were found in inflammatory conditions, and it is involved in the attenuation of the Th2-induced inflammatory response, probably via IL-33 sequestration. IL-33/ST2 signaling behaves as an intracellular system with participation in antigen-antigen response, autoimmunity, fibrosis processes and possibly RA pathogenesis. The active form of IL-33 is released after cell damage and it promotes macrophage activation, neutrophil migration to articular sites and production of metalloproteinases and cytokines by fibroblast-like synoviocytes. IL-33 stimulates naïve CD4 $+\mathrm{T}$ cells to differentiate into Th2 and induces the production of IL-5 and IL-3. IL-33 also promotes

(c) The Author(s). 2019 Open Access This article is distributed under the terms of the Creative Commons Attribution 4.0 International License (http://creativecommons.org/licenses/by/4.0/), which permits unrestricted use, distribution, and 
autoantibody-mediated mast cell activation and degranulation $[1,2]$. Significantly higher IL-33 levels were found in serum and synovial fluid of RA patients when compared with controls. IL-33 levels were correlated to IL-1 $\beta$, IL-6, C-reactive protein, DAS28, rheumatoid factor and anti-CCP. Treatment with antirheumatic agents reduced serum IL-33 levels [3-5]. Thus, IL-33 may be an acceptable biomarker and potential therapeutic target for RA.

IL-33/ST2 signaling also appears to play a role in atherosclerosis [6]. IL-33 and ST2 are expressed in human venous and coronary artery endothelium [7, 8]. Administration of IL-33 to apolipoprotein E-deficient mice reduced atherosclerotic plaque development. In contrast, mice treated with sST2 developed larger plaques. These results suggest that IL-33/ST2 may have protective effects in relation to atherosclerosis [7]. On the other hand, some studies showed that IL-33 may, on the contrary, be associated with progression of atherosclerotic plaques by increasing vascular permeability, inflammatory cytokine production and expression of the adhesion molecules in coronary artery $[8,9]$.

RA is an independent risk factor for early mortality and is associated with a high risk of death from cardiovascular disease (CVD), even after adjustment for traditional risk factors for coronary atherosclerotic disease [10-12]. The cause of the early and accelerated atherosclerosis has not been fully elucidated, but the combination of traditional and non-traditional risk factors is likely to be relevant $[10$, 13, 14]. Circulating inflammatory mediators may affect the arterial wall during the various stages of atherosclerosis development [15]. Several investigators reported that the association between systemic inflammation markers and vascular abnormalities was only found in the presence of traditional risk factors $[16,17]$.

Assessment of the carotid arteries using high-resolution ultrasound is one of the noninvasive procedures used to evaluate early preclinical atherosclerosis. Increased intima-media thickness (IMT) and presence of plaques are independently associated with cardiovascular risk factors and generalized atherosclerosis [18]. They are strong predictors of future cardiovascular events in overall population and in high-risk patients, such as those with RA [19-22].

Our study investigated the possible association between serum IL-33 and sST2 levels and subclinical carotid atherosclerosis in RA patients.

\section{Methods}

\section{Patients}

Adults with RA, defined according to the American College of Rheumatology (ACR) or ACR/European League Against Rheumatism classification criteria, with symptoms lasting for more than 6 months were invited to participate in the study. The exclusion criteria consisted of past or present angina, acute myocardial infarction, coronary revascularization procedures, coronary stenosis on angiography, stroke or transient ischemic attack, carotid stenosis and peripheral arterial insufficiency on angiography or ultrasonography; the presence of heart failure, atrial fibrillation, and implanted pacemaker or defibrillator; the presence of other connective tissue disorders (overlap syndromes), except for secondary Sjögren syndrome; and the presence of signs and symptoms of infection or recent history of infection.

\section{Methods}

The participants were subjected to a clinical evaluation that included a count of the number of swollen and painful joints. Disease-related information, laboratory test data, current and previous treatment records and the cumulative prednisone dose were obtained through interviews and a review of medical records.

Systemic arterial hypertension was defined as a systolic arterial pressure $\geq 140$, diastolic arterial pressure $\geq 90$ or the use of antihypertensive medication. Smoking was defined as the use of any amount of tobacco in the past 30 days, and ex-smokers were defined as those who abstained from tobacco use in the past 30 days. A family history of early CVD was defined as the presence of atherosclerotic artery disease among parents, siblings or children before the age of 55 for males and 65 for females [23]. Dyslipidemia was defined as the use of hypolipidemic agents, triglycerides $>150 \mathrm{mg} / \mathrm{dl}$, high-density lipoprotein (HDL) cholesterol $<50 \mathrm{mg} / \mathrm{dl}$ for women and $<40 \mathrm{mg} / \mathrm{dl}$ for men, or low-density lipoprotein (LDL) cholesterol $>160 \mathrm{mg} / \mathrm{dL}$ [23]. The LDL cut-off value was determined using cardiovascular risk stratification and the Framingham Risk Score [24], as recommended by the Brazilian Society of Cardiology [23]. Central obesity was defined as a waist circumference $\geq 94 \mathrm{~cm}$ for men and $\geq 80 \mathrm{~cm}$ for women. Metabolic syndrome was defined according to the criteria established by the International Diabetes Federation [25].

Hand/wrist and forefoot anteroposterior radiographs were taken within 12 months prior to or after the assessment. A single radiologist blinded to the patients' data analyzed the radiographs by calculating the total Sharp/ van der Heijde modified score. The intra-rater agreement was good (intraclass correlation coefficient: 0.958).

The participants were assessed using the Health Assessment Questionnaire Disability Index (HAQ-DI) validated for the Portuguese language and two $0-100 \mathrm{~mm}$ visual analog scales for pain and global disease activity. CDAI and DAS28, which are composite disease activity indices consisting of four variables, were calculated using the erythrocyte sedimentation rate (ERS) measured on the day of assessment and the patient-reported visual analog scale for disease activity.

\section{IL-33 and sST2 measurements}

Blood samples were collected from a peripheral vein, and the serum was separated from the sample. IL-33 
and sST2 were measured using an enzyme-linked immunosorbent assay (ELISA) according to the manufacturer's instructions (Human IL-33 DuoSet Economy Pack and sST2 DuoSet-ELISA sandwich assay, R\&D System Inc., Minneapolis, MN, USA).

\section{Carotid ultrasound}

The subclinical atherosclerosis of carotid arteries was assessed using B-mode ultrasound to detect atherosclerotic plaques and measure IMT according to previously established guidelines [22, 26]. A high-resolution Philips iE33 ultrasound machine with a 3-to-9 MHz linear probe and artery specific software was used. The left and right common internal and external carotid arteries were transversely and longitudinally scanned for atherosclerotic plaques, which were defined as focal structures protruding into the artery lumen that measured at least $0.5 \mathrm{~mm}$ and were greater than $50 \%$ of the adjacent IMT or showed an IMT over $1.5 \mathrm{~mm}$. The IMT was measured on the posterior wall of the left and right distal common carotid arteries at a plaque-free site one to two centimeters from the artery bifurcation. Images were obtained with adequate gain and depth adjustments along the longitudinal axis at a site where the artery segment was the most perpendicular to the ultrasound beam. Anterior, posterior or sternocleidomastoid access was utilized. The most rectilinear images with well-defined double-line patterns were selected for measurement. After completion of the test, IMT measurements were made on a $10-\mathrm{mm}$ common carotid artery segment using automatic border (lumen-intima and media-adventitia) detection software. The average of the measurements was calculated for the right and left arteries separately. For each patient, the highest average IMT calculated on the right or left artery was used in the statistical analysis. The parameters used to classify IMT as abnormal comprised the values obtained in the Multi-Ethnic Study of Atherosclerosis [22]. Values above the 75th percentile for sex, age, race, and IMT in the right or left artery were considered as abnormal.

A single professional with extensive technical experience who was blinded to the clinical status of the participants performed all of the tests. The intra-rater agreement was good (intraclass correlation coefficient of $98.7 \%$ for IMT measurements and a Kappa coefficient of $100 \%$ for plaque detection).

\section{Statistical analysis}

A descriptive analysis was performed using frequency distribution tables and central tendency measurements. All of the statistical analyses were performed with SPSS version 15.0 software.

A univariate analysis was used to investigate factors associated with the presence of atherosclerotic plaques. A Pearson's chi-square or Fisher's exact test was used to compare categorical variables, and Student's t-test or the non-parametric Mann-Whitney test was used to compare numerical variables. Distribution normality was assessed using the Kolmogorov-Smirnov test. Binary logistic regression was used in the multivariate analysis. Using the final model, the adjusted odd ratios (OR) with corresponding $95 \%$ confidence interval $(95 \% \mathrm{CI})$ were calculated. The model goodness of fit was assessed using the Hosmer-Lemeshow test.

A univariate analysis was used to investigate factors associated with IMT. The Mann-Whitney or Kruskal-Wallis test was used to compare categorical variables, and the Spearman's correlation coefficient was used to compare numerical variables. Non-parametric tests were selected because the IMT distribution was slightly skewed. A linear regression model was used in the multivariate analysis. The goodness of fit of the final model was assessed using the coefficient of determination $\left(\mathrm{R}^{2}\right)$ and diagnostic plots. The data were not transformed to obtain a normal distribution because the distribution of the model residuals for IMT was very close to normality.

An analysis of the residual plots indicated that the model was appropriate for the data.

Predictive variables with a $p$-value $<0.15$ in the univariate analysis were included in the multivariate model using forward stepwise selection. The significance level for the final model was set at $5 \%$.

\section{Results}

\section{Patient clinical and laboratory characteristics}

Between March 2012 and August 2013, a total of 102 patients were included in the study. The demographic and clinical characteristics of the patients and their medication use are provided in Table 1.

Based on their Framingham Risk Scores [24], 64 (62.7\%) participants were at high cardiovascular risk, and only $22(21.6 \%)$ patients met the LDL therapeutic goal established by the Brazilian Society of Cardiology Guideline [23] (Table 1). The median (interquartile range) IMT of the common carotid artery was 0.7 (0.6$0.8) \mathrm{mm}$. The IMT was elevated in $18.6 \%$ of patients. Atherosclerotic plaques were detected in 24 (23.5\%) participants (Table 2). A total of 36 participants (35.3\%) exhibited atherosclerotic plaques and/or increased IMT.

The serum IL-33 and sST2 levels were above the limit of detection in 68 (66.7\%) and 101 (99\%) participants, respectively (Table 2). No correlation was found between IL-33 and sST2 levels $(r=0.123 ; p=0.319)$.

\section{Factors associated with the occurrence of atherosclerotic plaques}

The participants with atherosclerotic plaques had an older average age (59.9 versus 54.2 years old; $p=0.014$ ) and longer mean disease duration (21.9 versus 16.3 years; 
Table 1 Demographic, clinical and laboratory characteristics of participants

\begin{tabular}{|c|c|}
\hline Variable & Value \\
\hline Age (years - mean $\pm S D$ ) & $55.5 \pm 10$ \\
\hline Age at onset of symptoms (years - mean \pm SD) & $37.9 \pm 11.9$ \\
\hline Disease length (years - mean $\pm S D$ ) & $17.6 \pm 9.5$ \\
\hline Female gender $(n(\%))$ & $94(92.5)$ \\
\hline Postmenopausal (n (\% female participants)) & $71(75.5)$ \\
\hline Non-white ethnicity $(n(\%))$ & $74(72.5)$ \\
\hline Seropositive RA $(n(\%))^{a}$ & $84(82.4)$ \\
\hline Extra-articular involvement ${ }^{\mathrm{b}}(n(\%))$ & $23(22.5)$ \\
\hline DAS28 (mean \pm SD) & $4 \pm 1.4$ \\
\hline CDAl (mean \pm SD) & $13.4 \pm 11.7$ \\
\hline HAQ-DI (median (IQR)) & $0.8(0.3-1.4)$ \\
\hline Sharp/van der Heijde score ${ }^{\complement}$ (median (IQR)) & $38(10-75.5)$ \\
\hline SAP/DAP (mmHg - mean \pm SD) & $123 \pm 13 / 77.5 \pm 8.6$ \\
\hline Waist circumference (cm - mean \pm SD) & $94.5 \pm 10.8$ \\
\hline $\mathrm{BMI}($ mean $\pm \mathrm{SD})$ & $27.5 \pm 4.7$ \\
\hline \multicolumn{2}{|l|}{ Medications in use (n patients (\%)) } \\
\hline Oral hypoglycemic agents and/or insulin & $14(13.7)$ \\
\hline Hypolipidemic agents & $28(27.5)$ \\
\hline Antihypertensives & $54(52.9)$ \\
\hline DMARDs & $91(89.2)$ \\
\hline Methotrexate & $66(64.7)$ \\
\hline Leflunomide & $42(41.2)$ \\
\hline Anti-TNFa & $15(14.7)$ \\
\hline Nonsteroidal anti-inflammatory drugs & $22(21.6)$ \\
\hline Prednisone & $62(60.8)$ \\
\hline Prednisone daily dose (mg - median (IQR)) & $2.5(0-5)$ \\
\hline Prednisone cumulative dose ( $\mathrm{g}-$ mean $\pm \mathrm{SD}$ ) & $21.8 \pm 15.7$ \\
\hline \multicolumn{2}{|l|}{ Laboratory tests } \\
\hline $\mathrm{HDL}(\mathrm{mg} / \mathrm{dL}-$ mean $\pm \mathrm{SD})$ & $58.4 \pm 16.1$ \\
\hline $\mathrm{LDL}(\mathrm{mg} / \mathrm{dL}$ - mean $\pm \mathrm{SD})$ & $110.6 \pm 28$ \\
\hline $\mathrm{TC} / \mathrm{HDL}(\text { median }(\mathrm{IQR}))^{\mathrm{d}}$ & $3.5(2.8-4.1)$ \\
\hline Triglycerides (mg/dL - median (IQR)) & $112(81-165.5)$ \\
\hline Fasting glucose (mg/dL - median (IQR)) & 89 (79-97) \\
\hline CRP (mg/L - median (IQR)) & $8.3(4.9-16.9)$ \\
\hline ESR (mm/h - median (IQR)) & $22(15-32)$ \\
\hline \multicolumn{2}{|l|}{ Traditional risk factors for CAD (n (\%)) } \\
\hline Current smoker & $12(11.8)$ \\
\hline Diabetes mellitus & $17(16.7)$ \\
\hline Family history of early CVD & $18(17.6)$ \\
\hline Metabolic syndrome & $53(52)$ \\
\hline Systemic arterial hypertension & $60(58.8)$ \\
\hline Dyslipidemia & $65(63.7)$ \\
\hline Central obesity & $88.2(90)$ \\
\hline
\end{tabular}

Table 1 Demographic, clinical and laboratory characteristics of participants (Continued)

\begin{tabular}{ll}
\hline Variable & Value \\
\hline $\begin{array}{l}\text { Global Risk Score (Framingham) (Ref. 67) } \\
\text { (median (IQR)) }\end{array}$ & $7.1(4.1-11.6)$ \\
High cardiovascular risk (Ref. 65) ( $($ (\%)) & $64(62.7)$ \\
LDL within therapeutic goal (BSC) (Ref. 65) & $22(21.6)$
\end{tabular}
(n (\%))

$S D$ standard deviation, $R A$ rheumatoid arthritis, DAS28 Disease Activity Score based on 28 joints, CDAI Clinical Disease Activity Index, HAQ-DI Health Assessment Questionnaire Disability Index, IQR interquartile range, $B M I$ body mass index, $D M A R D$ s disease-modifying antirheumatic drugs, $C A D$ coronary artery disease, CRP C-reactive protein, ESR erythrocyte sedimentation rate, CVD cardiovascular disease; and BSC Brazilian Society of Cardiology

a number of patients with positive rheumatoid factor and/or anti-CCP in any titer at any time during the clinical course of disease

${ }^{b}$ number of patients with extra-articular involvement at any time during the clinical course of disease

total Sharp/Van der Heijde modified score (0-448)

dotal cholesterol-to-HDL ratio

$p=0.011$ ). The prevalence of atherosclerotic plaques was higher in postmenopausal women than in non-postmenopausal women $(29.6 \%$ versus $8.7 \%$; $p=0.043)$. The median IMT was higher in patients with atherosclerotic plaques $(0.8 \mathrm{~mm}$ versus $0.6 \mathrm{~mm} ; p=0.001)$. No patient with LDL values within the therapeutic goal range exhibited plaques, while the prevalence of plaques in the remaining participants was $30 \%(p=0.003)$. The Framingham Risk Score values were higher for patients with atherosclerotic plaques ( 8.7 versus $6.3, p=0.048$ ) (Table 3 ).

There was no association between IL-33 and sST2 levels and the occurrence of atherosclerotic plaques $(p>0.05)$ (Table 3). None of the other factors we assessed correlated with plaque occurrence.

The multivariate analysis showed that each $0.1-\mathrm{mm}$ increase in IMT caused a 5.3-fold increase in the odds for plaque occurrence (OR: 53.2; 95\%CI 2.88-983.37). Each additional year of disease duration increased the odds of plaque occurrence by $6 \%$ (OR: 1.06; 95\%CI 1.01-1.12).

Table 2 Results of carotid artery ultrasounds and IL-33 and SST2 measurements

\begin{tabular}{ll}
\hline Variable & Value \\
\hline IMT - CCA (mm - median (IQR)) & $0.7(0.6-0.8)$ \\
Increased IMT (n (\%)) & $19(18.6)$ \\
Atherosclerotic plaque (n (\%)) & $24(23.5)$ \\
IL-33 (pg/mL - median (IQR)) & a \\
IL-33 (pg/mL - median (IQR) $)^{\mathrm{b}}$ & $32.1(0-78.7)$ \\
sST2 (pg/mL - median (IQR)) & $69.1(31.6-114.5)$ \\
IL-33/sST2 (median (IQR) $)^{\mathrm{d}}$ & $469.8(336.3-651)$ \\
\hline
\end{tabular}

IMTintima-media thickness, CCA common carotid artery; and IQR interquartile range. According to the manufacturer, the minimum detectable concentration of IL-33 and SST2 was 23.4 and $31.2 \mathrm{pg} / \mathrm{ml}$, respectively

alevels below the limit of detection were considered as zero

bonly considering the 68 participants with levels above the limit of detection |'only considering the 101 participants with levels above the limit of detection d IL-33-to-sST2 ratio 
Table 3 Comparison of patients with and without atherosclerotic plaques

\begin{tabular}{|c|c|c|c|}
\hline Variable & $\begin{array}{l}\text { Plaques absent } \\
(n=78)\end{array}$ & $\begin{array}{l}\text { Plaques present } \\
(n=24)\end{array}$ & $p$-value \\
\hline Age (years - mean \pm SD) & $54.2 \pm 9.8$ & $59.9 \pm 9.7$ & $0.014^{a}$ \\
\hline Disease length (years - mean $\pm S D$ ) & $16.3 \pm 9.7$ & $21.9 \pm 8$ & $0.011^{\mathrm{a}}$ \\
\hline $\begin{array}{r}\text { Postmenopausal (n (\%)): No } \\
\text { Yes }\end{array}$ & $\begin{array}{l}21(91.3) \\
50(70.4)\end{array}$ & $\begin{array}{l}2(8.7) \\
21(29.6)\end{array}$ & $0.043^{b}$ \\
\hline $\begin{array}{r}\text { LDL within goal (Ref. 65) (n (\%)) }{ }_{\text {Yes }} \\
\text { Yes }\end{array}$ & $\begin{array}{l}56(70) \\
22(100)\end{array}$ & $\begin{array}{l}24(30) \\
0(0)\end{array}$ & $0.003^{b}$ \\
\hline Global CVR score (median (IQR)) & $6.3(2.9-11.6)$ & $8.7(6.2-11.8)$ & $0.048^{\mathrm{c}}$ \\
\hline IMT (mm - median (IQR)) & $0.6(0.6-0.8)$ & $0.8(0.7-0.9)$ & $0.001^{c}$ \\
\hline $\begin{array}{r}\text { IL-33 (n (\%)) })^{\text {d: positive }} \\
\text { negative }\end{array}$ & $\begin{array}{l}52(76.5) \\
26(76.5)\end{array}$ & $\begin{array}{l}16(23.5) \\
8(23.5)\end{array}$ & $1^{b}$ \\
\hline IL-33 (pg/mL - median (IQR) $)^{\mathrm{e}}$ & $33.1(0-78.7)$ & $12.1(0-85.8)$ & $0.856^{c}$ \\
\hline IL-33 (pg/mL - median $(\mathrm{QQR}))^{\mathrm{f}}$ & $69.1(33.1-124.3)$ & $70.6(12.1-90.1)$ & $0.745^{c}$ \\
\hline sST2 $(\mathrm{pg} / \mathrm{mL}-\text { median }(\mathrm{IQR}))^{\mathrm{g}}$ & $461.7(316.6-651)$ & 485.9 (372.9-649) & $0.675^{c}$ \\
\hline IL-33/sST2 (median (IQR) $)^{\mathrm{h}}$ & $0.1(0-0.3)$ & $0.1(0-0.3)$ & $0.965^{c}$ \\
\hline
\end{tabular}

${ }^{a}$ t-test; ${ }^{b}$ chi-square; ${ }^{c}$ Mann-Whitney test

$S D$ standard deviation, NPJ number of painful joints upon physical examination, IQR interquartile range, SAH systemic arterial hypertension, $C V R$ cardiovascular risk, NSAIDs nonsteroidal anti-inflammatory drugs; and IMT intima-media thickness

dIL-33 positive: serum IL-33 $\geq 23.4 \mathrm{pg} / \mathrm{mL}$; and IL-33 negative: serum IL-33 $<23.4 \mathrm{pg} / \mathrm{mL}$

elevels below the limit of detection were considered as zero

fonly considering the 68 participants with levels above the limit of detection

${ }^{g}$ data from the 101 participants with detectable levels

hIL-33-to-sST2 ratio

\section{Factors associated with intima-media thickness}

Significant direct correlations were found between IMT and patient age $(\mathrm{r}=0.613 ; p<0.001)$, disease duration $(r=$ $0.224 ; p=0.024)$ and age at onset of RA symptoms ( $\mathrm{r}=$ $0.334 ; p=0.001)$. Similarly, IMT correlated with systolic arterial pressure $(\mathrm{r}=0.282 ; p=0.004)$, fasting glucose $(\mathrm{r}=$ $0.264 ; p=0.008)$ and Framingham Risk Score $(\mathrm{r}=0.591 ; p$
$<0.001)$. IMT inversely correlated with daily prednisone dose $(\mathrm{r}=-0.205 ; p=0.039)$ (Table 4).

The IMT was higher in patients with a history of extra-articular involvement $(p=0.014)$, systemic arterial hypertension $(p=0.001)$, diabetes mellitus $(p=0.003)$, and metabolic syndrome $(p=0.037)$. Within women, the IMT was higher in those who were postmenopausal $(p$

Table 4 Correlation of IMT with clinical and laboratory characteristics

\begin{tabular}{lll}
\hline Variable & Coefficient $^{\mathrm{a}}$ & $p$-value \\
\hline Age (years) & 0.613 & $<0.001$ \\
Disease length (years) & 0.224 & 0.024 \\
Age at onset of symptoms (years) & 0.334 & 0.001 \\
Time since onset of symptoms to 1st rheumatology visit (years) & 0.204 & 0.040 \\
Fasting glucose (mg/dL) & 0.263 & 0.008 \\
SAP (mmHg) & 0.282 & 0.004 \\
Global Cardiovascular Risk Score & 0.591 & $<0.001$ \\
Current prednisone daily dose & -0.205 & 0.039 \\
IL-33 (pg/mL) & -0.77 & 0.439 \\
IL-33 (pg/mL) & -0.035 & 0.775 \\
sST2 $(\mathrm{pg} / \mathrm{mL})^{d}$ & 0.002 & 0.981 \\
IL-33/sST2** & -0.071 & 0.566
\end{tabular}



$I M T$ intima-media thickness, IQR interquartile range, SD standard deviation, CRP C-reactive protein; and SAP systemic arterial pressure

blevels below the limit of detection were considered as zero

conly considering the 68 participants with levels above the limit of detection

data from the 101 participants with detectable levels

e IL-33-to-sST2 ratio 
$=0.001)$. The IMT was also higher in patients with a high cardiovascular risk according to the Framingham Risk Score $(p<0.001)$. In contrast, patients using methotrexate (MTX) and those with LDL values within the therapeutic goal range had a lower IMT ( $p=0.005$ and 0.012 , respectively) (Table 5).

None of the other factors we assessed, including serum IL-33 and sST2 levels and the IL-33/sST2 ratio, were associated with IMT (Tables 4 and 5).

The variables remaining in the final model, i.e., those associated with IMT, included age $(p=0.024 ; 95 \%$ CI 0 $0.007)$, Framingham Risk Score $(p<0.001$; $95 \%$ CI $0.007-$ $0.016)$ and MTX use $(p=0.015 ; 95 \%$ CI -0.117 to 0.013 ). Each additional year of patient age was associated with a $0.004 \mathrm{~mm}$ increase in IMT. Each one-point increase in the Framingham Risk Score was associated with a $0.012 \mathrm{~mm}$ increase in IMT. Patients using MTX at the time of assessment exhibited a $0.065 \mathrm{~mm}$ reduction in IMT. The model explained $45.2 \%$ of the data variability and had a satisfactory goodness of fit as evidenced by the diagnostic plots.

\section{Discussion}

We did not find an association between IL-33 or its soluble receptor and the presence of subclinical atherosclerosis in our RA patients. Due to the possible fluctuations in IL-33 and sST2 levels during the course of the disease, a single measurement may not accurately reflect the role of these factors in vascular morphology abnormalities and plaque development over time. IL-33 is released after the occurrence of cell damage and then binds to its receptor and promotes cell activation; thus, IL-33 and sST2 may only have a significant effect during acute cardiovascular events. Therefore, the main limitation of the present study was to make a single serum measure of IL-33 and sST2. A single dosage may not be the most appropriate to study the association of the biomarkers in question with the development of atherosclerosis over time.

IL-33 and sST2 are involved in the pathogenesis of RA [1] and can serve as markers of inflammation and disease activity [3,5]. Similarly, IL-33 and sST2 participate in atherosclerosis development and cardiac remodeling

Table 5 Correlation of IMT with demographic, clinical and laboratory characteristics

\begin{tabular}{|c|c|c|c|}
\hline Variable & & IMT (mm - median (IQR)) & $P$-value \\
\hline \multirow[t]{2}{*}{ Postmenopausal } & No & $0.60(0.55-0.65)$ & $0.001^{a}$ \\
\hline & Yes & $0.71(0.6-0.8)$ & \\
\hline \multirow[t]{2}{*}{ Extra-articular involvement } & No & $0.65(0.58-0.76)$ & $0.014^{\mathrm{a}}$ \\
\hline & Yes & $0.72(0.63-0.88)$ & \\
\hline \multirow[t]{2}{*}{$\mathrm{SAH}$} & Absent & $0.60(0.55-0.71)$ & $0.001^{\mathrm{a}}$ \\
\hline & Present & $0.72(0.63-0.81)$ & \\
\hline \multirow[t]{2}{*}{ Using antihypertensives } & No & $0.62(0.56-0.71)$ & $0.001^{a}$ \\
\hline & Yes & $0.73(0.63-0.81)$ & \\
\hline \multirow[t]{2}{*}{ Diabetes mellitus } & Absent & $0.65(0.58-0.76)$ & $0.003^{\mathrm{a}}$ \\
\hline & Present & $0.84(0.63-0.95)$ & \\
\hline \multirow[t]{2}{*}{ Using hypoglycemic agents/insulin } & No & $0.65(0.58-0.76)$ & $0.001^{a}$ \\
\hline & Yes & $0.84(0.7-1.02)$ & \\
\hline \multirow[t]{2}{*}{ LDL within goal } & No & $0.7(0.6-0.8)$ & $0.012^{\mathrm{a}}$ \\
\hline & Yes & $0.6(0.6-0.7)$ & \\
\hline \multirow[t]{2}{*}{ Metabolic syndrome } & Absent & $0.64(0.58-0.74)$ & $0.037^{\mathrm{a}}$ \\
\hline & Present & $0.71(0.6-0.84)$ & \\
\hline \multirow[t]{2}{*}{ Using methotrexate } & No & $0.75(0.62-0.87)$ & $0.005^{\mathrm{a}}$ \\
\hline & Yes & $0.63(0.58-0.73)$ & \\
\hline \multirow[t]{3}{*}{ CVR classification ${ }^{c}$} & High & $0.73(0.61-0.84)$ & $<0.001^{\mathrm{b}}$ \\
\hline & Intermediate & $0.71(0.64-0.77)$ & \\
\hline & Low & $0.6(0.54-0.64)$ & \\
\hline \multirow[t]{2}{*}{ IL-33 positive ${ }^{d}$} & No & $0.69(0.59-0.85)$ & $0.449^{a}$ \\
\hline & Yes & $0.66(0.59-0.78)$ & \\
\hline
\end{tabular}


$[6,27]$. The relationship between serum IL-33 and its soluble receptor with atherosclerosis in RA patients requires further study. It is not currently possible to determine if IL-33 participates in both RA and atherosclerosis via antagonistic effects on vessels, acts as a marker of inflammation in RA and/or exerts protective effects against atherosclerosis. Indeed, thorough research on the complex interactions between IL-33/sST2, atherosclerosis and RA is necessary.

The serum IL-33 level was undetectable in approximately one-third of patients. In a study by Matsuyama and colleagues, the IL-33 level was above the limit of detection in only $50.8 \%$ of patients, and $94 \%$ of the participants used disease-modifying antirheumatic drugs (DMARDs) [3]. Therefore, the low IL-33 levels found in our study may be due to the use of at least one DMARD in $90 \%$ of patients.

In the present study, 36 (35.3\%) participants had increased IMT and/or atherosclerotic plaques. Due to its independent association with generalized atherosclerosis and future cardiac events, IMT was selected as an indirect marker of early vascular morphology abnormalities in RA patients without a history of manifest atherosclerotic disease [18-22]. Similarly, plaque occurrence was investigated because it can be used to identify individuals at higher risk of coronary events in populations without coronary atherosclerotic disease [28]. Awareness of the presence of asymptomatic vascular morphological abnormalities may motivate patients to change their lifestyle and improve their adherence to treatment [29].

Both RA-related, e.g., disease duration and MTX use, and traditional, e.g., age and Framingham Risk Score, risk factors for coronary atherosclerotic disease were associated with the presence of subclinical atherosclerosis. These findings agree with the hypothesis that the interaction between RA-related and traditional risk factors increases a patient's cardiovascular morbidity and mortality in comparison to the overall population $[10,13,14,16]$.

Patients with atherosclerotic plaques had a longer RA disease duration and higher median IMT. Indeed, longer disease duration has been associated with plaque occurrence in RA [30]. Thus, disease duration may serve as an indirect marker of cumulative inflammation. Cross-sectional studies conducted in the overall population found a positive correlation between common carotid artery IMT and the presence of carotid plaques [29, 31, 32]. This association was also detected in populations of RA patients [30, 33].

MTX use was protective against intima-media thickening. This finding is in agreement with previous studies and with the fact that MTX has been shown to have cardioprotective effects. MTX also improves the lipid profile, mainly by increasing HDL levels. However, this improved lipid profile could be due to the control of inflammation or a direct effect of the drug [34, 35].
Age is an essential determinant of CVD [11]. In addition, age is one of the strongest determinants of IMT, which increases 0.01 to $0.02 \mathrm{~mm}$ per year in the overall population [31,36]. In agreement with previous studies in RA patients, we determined that IMT increased with age $[30,34,37,38]$. Our multivariate analysis did not reveal any significant correlations between IMT and any other single traditional risk factor. However, an independent correlation was found between IMT and Framingham Risk Score, which combines several risk factors.

RA-related chronic inflammation plays a crucial role in accelerated atherosclerosis [15]. Similar to previous studies, none of the inflammation or disease activity markers that we tested (ESR, C-reactive protein, DAS28 and CDAI) correlated with plaque occurrence or IMT $[30,37,38]$. A possible explanation for this lack of association is that RA-related inflammation fluctuates, and thus, the assessment of biomarkers in cross-sectional studies may not accurately reflect the cumulative effect of chronic inflammation on the vascular wall $[34,39]$.

Distinct factors were independently associated with IMT and the presence of carotid plaques. This discrepancy suggests that although IMT and plaque occurrence are correlated phenomena, they correspond to different stages and aspects of atherogenesis and thus have different determinants $[28,29,32,40]$. Diffuse adaptive thickening of the carotid wall, which occurs in response to aging and systemic arterial hypertension, is a more accurate reflection of arteriosclerosis than plaque formation. The latter is a focal process related to atherosclerotic phenomena, such as inflammation, oxidation and endothelial dysfunction $[28,40]$. In the present study, systolic arterial pressure and systemic arterial hypertension were associated with IMT in our univariate analysis but were not robust enough to constitute independent factors in the final model.

\section{Conclusions}

In view of the current evidence of IL-33/sST2 system participation in the pathogenesis and evolution of both RA and atherosclerotic disease, this study was designed. However, no association between IL-33/sST2 serum levels and subclinical atherosclerosis in patients with established RA was found. Traditional risk factors for atherosclerosis and rheumatoid arthritis duration were associated with intima-media thickness and plaque occurrence; methotrexate use was associated with a lower intima-media thickness. All these factors were previously described as being associated with subclinical atherosclerosis in RA. There have been few clinical studies evaluating the relationship between IL-33 and subclinical atherosclerosis. The importance of determining the role of specific cytokines in RA and their relationship to cardiovascular disease lies in the fact that this understanding may present in the future a clinical application in 
determining risk and prognostic markers, as well as identifying new therapeutic targets.

\section{Abbreviations}

ACR: American College of Rheumatology; Cl: Confidence interval; CVD: Cardiovascular disease; DMARDs: Disease-modifying antirheumatic drugs; ELISA: Enzyme-linked immunosorbent assay; ERS: Erythrocyte sedimentation rate; HAQ-DI: Health Assessment Questionnaire Disability Index; HDL: High-density lipoprotein cholesterol; IL: Interleukin; IMT: Intimamedia thickness; LDL: Low-density lipoprotein; MTX: Methotrexate; OR: Odd ratios; RA: Rheumatoid arthritis; sST2: Soluble ST2 receptor; Th2: Type 2 T helper lymphocytes

\section{Acknowledgements}

Not applicable.

\section{Funding}

This work was supported by Fundação de Amparo a Pesquisa do Estado de Minas Gerais (FAPEMIG) (APQ-00765-13) (M.V.A.), Conselho Nacional de Desenvolvimento Cientıfico e Técnico (CNPq) (473390/2013-2) (M.V.A.), and Pró-reitoria de Pesquisa/UFMG (PRPq/UFMG), Brazil. MAR and CGMCT were supported, respectively, by scientific initiation scholarship program (PROBIC) FAPEMIG) and postdoctoral fellowship (FAPEMIG)

\section{Availability of data and materials}

The datasets used and/or analysed during the current study are available from the corresponding author on reasonable request.

\section{Authors' contributions}

MRCP, AMK and MVA designed the study and wrote the paper. MRCP and AMK worked on the background research and on the analysis and interpretation of the results. MRCP, AJS, WCT, MAR, CGMCT and MVA worked on the acquisition of data. All authors read and approved the final manuscript.

\section{Ethics approval and consent to participate}

Prior to undergoing any procedures, all of the patients who were included the present study signed an informed consent form approved by the research ethics committee at the Universidade Federal de Minas Gerais. This study was conducted in accordance with the ethical standards of the local committee and with the Declaration of Helsinki.

\section{Consent for publication}

Not applicable.

\section{Competing interests}

The authors declare that they have no competing interest.

\section{Publisher's Note}

Springer Nature remains neutral with regard to jurisdictional claims in published maps and institutional affiliations.

\section{Author details \\ ${ }^{1}$ School of Medicine, Federal University of Minas Gerais (Universidade Federal de Minas Gerais - UFMG), Avenida Alfredo Balena, 190, Bairro Santa Efigênia, Belo Horizonte, Minas Gerais CEP 30130-100, Brazil. ${ }^{2}$ Conrad Diagnostic Imaging (Conrad Diagnóstico por Imagem), Rua Rio Grande do Norte, 77, Bairro Santa Efigênia, Belo Horizonte, MG CEP: 30130-130, Brazil. ${ }^{3}$ Ecoar Diagnostic Medicine (Ecoar Medicina Diagnóstica), Avenida do Contorno, 6760, Bairro Santo Antônio, Belo Horizonte, MG CEP: 30110-044, Brazil.}

Received: 15 August 2018 Accepted: 26 March 2019

Published online: 03 April 2019

\section{References}

1. Schmitz J, Owyang A, Oldham E, Song Y, Murphy E, McClanahan TK, et al. IL-33, an interleukin-1-like cytokine that signals via the IL-1 receptor-related protein ST2 and induces T helper type 2-associated cytokines. Immunity. 2005;23(5):479-90.
2. Verri WA, Souto FO, Vieira SM, Almeida SC, Fukada SY, Xu D, et al. IL-33 induces neutrophil migration in rheumatoid arthritis and is a target of antiTNF therapy. Ann Rheum Dis. 2010;69(9):1697-703.

3. Matsuyama Y, Okazaki H, Tamemoto H, Kimura H, Kamata Y, Nagatani K, et al. Increased levels of interleukin 33 in sera and synovial fluid from patients with active rheumatoid arthritis. J Rheumatol. 2010;37(1):18-25.

4. Hong YS, Moon SJ, Joo YB, Jeon CH, Cho ML, Ju JH, et al. Measurement of interleukin-33 (IL-33) and IL-33 receptors (SST2 and ST2L) in patients with rheumatoid arthritis. J Korean Med Sci. 2011;26(9):1132-9.

5. Kageyama Y, Torikai E, Tsujimura K, Kobayashi M. Involvement of IL-33 in the pathogenesis of rheumatoid arthritis: the effect of etanercept on the serum levels of IL-33. Mod Rheumatol. 2012;22(1):89-93.

6. Miller AM, Liew FY. The IL-33/ST2 pathway--a new therapeutic target in cardiovascular disease. Pharmacol Ther. 2011;131(2):179-86.

7. Miller AM, Xu D, Asquith DL, Denby L, Li Y, Sattar N, et al. IL-33 reduces the development of atherosclerosis. J Exp Med. 2008;205(2):339-46.

8. Choi YS, Choi HJ, Min JK, Pyun BJ, Maeng YS, Park H, et al. Interleukin-33 induces angiogenesis and vascular permeability through ST2/TRAF6mediated endothelial nitric oxide production. Blood. 2009:114(14):3117-26.

9. Demyanets S, Konya V, Kastl SP, Kaun C, Rauscher S, Niessner A, et al. Interleukin-33 induces expression of adhesion molecules and inflammatory activation in human endothelial cells and in human atherosclerotic plaques. Arterioscler Thromb Vasc Biol. 2011:31(9):2080-9.

10. Salmon JE, Roman MJ. Subclinical atherosclerosis in rheumatoid arthritis and systemic lupus erythematosus. Am J Med. 2008;121(10 Suppl 1):S3-8.

11. Kremers HM, Crowson CS, Therneau TM, Roger VL, Gabriel SE. High ten-year risk of cardiovascular disease in newly diagnosed rheumatoid arthritis patients: a population-based cohort study. Arthritis Rheum. 2008;58(8):2268-74.

12. Peters MJ, van Halm VP, Voskuyl AE, Smulders YM, Boers M, Lems WF, et al. Does rheumatoid arthritis equal diabetes mellitus as an independent risk factor for cardiovascular disease? A prospective study. Arthritis Rheum. 2009; 61(11):1571-9.

13. Frostegård J. Atherosclerosis in patients with autoimmune disorders Arterioscler Thromb Vasc Biol. 2005;25(9):1776-85.

14. Liang KP. Cardiovascular risk in rheumatoid arthritis (RA): does it matter if RA is diagnosed in early or late age? J Rheumatol. 2013:40(12):1945-7.

15. Sattar N, McCarey DW, Capell H, McInnes IB. Explaining how "high-grade" systemic inflammation accelerates vascular risk in rheumatoid arthritis. Circulation. 2003;108(24):2957-63.

16. del Rincón I, Freeman GL, Haas RW, O'Leary DH, Escalante A. Relative contribution of cardiovascular risk factors and rheumatoid arthritis clinical manifestations to atherosclerosis. Arthritis Rheum. 2005;52(11):3413-23.

17. Zampeli E, Protogerou A, Stamatelopoulos K, Fragiadaki K, Katsiari CG, Kyrkou K, et al. Predictors of new atherosclerotic carotid plaque development in patients with rheumatoid arthritis: a longitudinal study. Arthritis Res Ther. 2012;14(2):R44

18. Hodis HN, Mack WJ, LaBree L, Selzer RH, Liu CR, Liu CH, et al. The role of carotid arterial intima-media thickness in predicting clinical coronary events. Ann Intern Med. 1998:128(4):262-9.

19. O'Leary DH, Polak JF, Kronmal RA, Manolio TA, Burke GL, Wolfson SK. Carotid-artery intima and media thickness as a risk factor for myocardial infarction and stroke in older adults. Cardiovascular health study collaborative research group. N Engl J Med. 1999:340(1):14-22.

20. Sandoo A, van Zanten JJ, Metsios GS, Carroll D, Kitas GD. The endothelium and its role in regulating vascular tone. Open Cardiovasc Med J. 2010:4:302-12.

21. Lorenz MW, von Kegler S, Steinmetz H, Markus HS, Sitzer M. Carotid intimamedia thickening indicates a higher vascular risk across a wide age range: prospective data from the carotid atherosclerosis progression study (CAPS). Stroke. 2006:37(1):87-92.

22. Stein JH, Korcarz CE, Hurst RT, Lonn E, Kendall CB, Mohler ER, et al. Use of carotid ultrasound to identify subclinical vascular disease and evaluate cardiovascular disease risk: a consensus statement from the American Society of Echocardiography carotid intima-media thickness task force. Endorsed by the Society for Vascular Medicine. J Am Soc Echocardiogr. 2008;21(2):93-111 quiz 89-90.

23. Xavier HT, Izar MC, Faria Neto JR, Assad MH, Rocha VZ, Sposito AC, et al. V Diretriz Brasileira de Dislipidemias e Prevenção da Aterosclerose. Arq Bras Cardiol. 2013:101(4 Suppl 1):1-20.

24. D'Agostino RB, Vasan RS, Pencina MJ, Wolf PA, Cobain M, Massaro JM, et al. General cardiovascular risk profile for use in primary care: the Framingham heart study. Circulation. 2008;117(6):743-53. 
25. Alberti KG, Zimmet P, Shaw J. Metabolic syndrome--a new world-wide definition. A consensus statement from the international diabetes federation. Diabet Med. 2006;23(5):469-80.

26. Touboul PJ, Hennerici MG, Meairs S, Adams H, Amarenco P, Bornstein N, et al. Mannheim carotid intima-media thickness and plaque consensus (20042006-2011). An update on behalf of the advisory board of the 3rd, 4th and 5th watching the risk symposia, at the 13th, 15th and 20th European stroke conferences, Mannheim, Germany, 2004, Brussels, Belgium, 2006, and Hamburg, Germany, 2011. Cerebrovasc Dis. 2012;34(4):290-6.

27. Kunes P, Holubcová Z, Kolácková M, Krejsek J. The counter-regulation of atherogenesis: a role for interleukin-33. Acta Med (Hradec Kralove). 2010; 53(3):125-9.

28. Plichart M, Celermajer DS, Zureik M, Helmer C, Jouven X, Ritchie $K$, et al. Carotid intima-media thickness in plaque-free site, carotid plaques and coronary heart disease risk prediction in older adults. The Three-City study. Atherosclerosis. 2011;219(2):917-24.

29. Ebrahim S, Papacosta O, Whincup P, Wannamethee G, Walker M, Nicolaides AN, et al. Carotid plaque, intima media thickness, cardiovascular risk factors, and prevalent cardiovascular disease in men and women: the British regional heart study. Stroke. 1999;30(4):841-50.

30. Gonzalez-Juanatey C, Llorca J, Testa A, Revuelta J, Garcia-Porrua C, Gonzalez Gay MA. Increased prevalence of severe subclinical atherosclerotic findings in long-term treated rheumatoid arthritis patients without clinically evident atherosclerotic disease. Medicine (Baltimore). 2003;82(6):407-13.

31. Veller MG, Fisher CM, Nicolaides AN, Renton S, Geroulakos G, Stafford NJ, et al. Measurement of the ultrasonic intima-media complex thickness in normal subjects. J Vasc Surg. 1993;17(4):719-25.

32. Zureik M, Ducimetière P, Touboul PJ, Courbon D, Bonithon-Kopp C, Berr C, et al. Common carotid intima-media thickness predicts occurrence of carotid atherosclerotic plaques: longitudinal results from the aging vascular study (EVA) study. Arterioscler Thromb Vasc Biol. 2000;20(6):1622-9.

33. Pereira I, Laurindo I, Burlingame R, Anjos L, Viana V, Leon E, et al. Autoantibodies do not influence development of atherosclerotic plaques in rheumatoid arthritis. Joint Bone Spine. 2008;75(4):416-21.

34. Ristić GG, Lepić T, Glisić B, Stanisavljević D, Vojvodić D, Petronijević M, et al. Rheumatoid arthritis is an independent risk factor for increased carotid intima-media thickness: impact of anti-inflammatory treatment. Rheumatology (Oxford). 2010;49(6):1076-81.

35. Westlake SL, Colebatch AN, Baird J, Kiely P, Quinn M, Choy E, et al. The effect of methotrexate on cardiovascular disease in patients with rheumatoid arthritis: a systematic literature review. Rheumatology (Oxford). 2010;49(2):295-307.

36. Howard G, Sharrett AR, Heiss G, Evans GW, Chambless LE, Riley WA, et al. Carotid artery intimal-medial thickness distribution in general populations as evaluated by B-mode ultrasound. ARIC investigators. Stroke. 1993;24(9): 1297-304.

37. Kumeda Y, Inaba M, Goto H, Nagata M, Henmi Y, Furumitsu Y, et al. Increased thickness of the arterial intima-media detected by ultrasonography in patients with rheumatoid arthritis. Arthritis Rheum. 2002; 46(6):1489-97.

38. Alkaabi JK, Ho M, Levison R, Pullar T, Belch JJ. Rheumatoid arthritis and macrovascular disease. Rheumatology (Oxford). 2003:42(2):292-7.

39. Sandoo A, Chanchlani N, Hodson J, Smith JP, Douglas KM, Kitas GD. Classical cardiovascular disease risk factors associate with vascular function and morphology in rheumatoid arthritis: a six-year prospective study. Arthritis Res Ther. 2013;15(6):R203.

40. Kiechl S, Willeit J. The natural course of atherosclerosis. Part I: incidence and progression. Arterioscler Thromb Vasc Biol. 1999;19(6):1484-90.

\section{Ready to submit your research? Choose BMC and benefit from:}

- fast, convenient online submission

- thorough peer review by experienced researchers in your field

- rapid publication on acceptance

- support for research data, including large and complex data types

- gold Open Access which fosters wider collaboration and increased citations

- maximum visibility for your research: over $100 \mathrm{M}$ website views per year

At $\mathrm{BMC}$, research is always in progress.

Learn more biomedcentral.com/submissions 